\title{
MEK162 Enhances Antitumor Activity of 5-Fluorouracil and Trifluridine in KRAS-mutated Human Colorectal Cancer Cell Lines
}

\author{
JUN GONG $^{1}$, YUAN CHEN ${ }^{2}$, LIXIN YANG $^{3}$, RAJU PILLAI $^{3}$, SENJI SHIRASAWA $^{4}$ and MARWAN FAKIH ${ }^{5}$ \\ Departments of ${ }^{1}$ Medical Oncology, ${ }^{2}$ Molecular Medicine, and \\ ${ }^{3}$ Pathology, City of Hope National Medical Center, Duarte, CA, U.S.A.; \\ ${ }^{4}$ Department of Cell Biology, Faculty of Medicine, Fukuoka University, Fukuoka, Japan; \\ ${ }^{5}$ Medical Oncology and Experimental Therapeutics, \\ City of Hope Comprehensive Cancer Center, Duarte, CA, U.S.A.
}

\begin{abstract}
Background: Preclinical evidence demonstrates that mitogen-activated protein kinase kinase (MEK)/ extracellular signal-regulated kinase (ERK) pathway inhibition increases sensitivity to 5-fluorouracil (5-FU) in colorectal cancer $(C R C)$ cell lines and xenografts. Here, we aimed to investigate how CRC cell sensitivity to this combination is correlated to Kirsten rat sarcoma (KRAS) and proto-oncogene $B$-rapidly accelerated fibrosarcoma (BRAF) mutation, that are common in CRC and often lead to resistance to chemotherapy. Materials and Methods: Wild-type and mutant KRAS/BRAF human CRC cell lines were treated with escalating doses of 5 FU or trifluridine with MEK162 (MEK1/2 inhibitor) for $72 \mathrm{~h}$. Cell viability was assessed by 3-(4,5-dimethylthiazol-2-yl)-2,5diphenyltetrazolium bromide assay and synergism expressed by the combination index was calculated using CalcuSyn. Results: Evidence of synergistic antitumor activity was observed for the majority of human CRC cell lines treated with MEK162 plus 5-FU (4/6) or trifluridine (7/9). Synergism was greater in $K R A S$ - or BRAF-mutant cell lines compared to wild-type KRAS/BRAF CRC cell lines. Conclusion: The combination of $M E K$ inhibition and trifluridine is worthwhile advancing in clinical development, particularly for treatment-refractory KRAS- or BRAF-mutated metastatic CRC.
\end{abstract}

This article is freely accessible online.

Correspondence to: Marwan Fakih, Medical Oncology and Experimental Therapeutics, City of Hope Comprehensive Cancer Center, Building 51, Room 127, 1500 E Duarte St, Duarte, CA 91010, U.S.A. Tel: +1 6262564673, Fax: +1 6263018233, e-mail: mfakih@coh.org

Key Words: MEK162, 5-fluorouracil, trifluridine, KRAS, colorectal cancer, preclinical.
Fluorouracil, or 5-fluorouracil (5-FU), is a fluorinated pyrimidine whose anticancer properties are thought to be due to its ability to inhibit the rate-limiting enzyme in pyrimidine nucleotide synthesis, thymidylate synthase (1). In the current approach to treatment of metastatic CRC (mCRC), 5-FU remains a critical component to combination cytotoxic therapy and forms the backbone of treatment for regimens such as FOLFIRI (5-FU, leucovorin (LV), and irinotecan), FOLFOX (5-FU, LV, and oxaliplatin), and FOLFOXIRI (5FU, LV, oxaliplatin, and irinotecan) (2-5).

Another nucleoside analog, trifluridine, has been also demonstrated to possess ability for incorporation into DNA and inhibit thymidylate synthase (6). Trifluridine represents the active antitumor component of TAS-102, which is formed by the combination of trifluridine and tipiracil, an inhibitor of thymidine phosphorylase that prevents the degradation of trifluridine (6). Development of this agent has recently led to its approval as a systemic therapy for treatment-refractory mCRC given its overall survival (OS) benefit compared to placebo in the phase III RECOURSE trial (7).

Preclinical evidence demonstrates that mitogen-activated protein kinase (MAPK) kinase (MEK)/extracellular signalregulated kinase (ERK) signaling is associated with increased resistance to fluoropyrimidines across several tumor types including breast, prostate, and hepatocellular carcinoma (811). Furthermore, MEK/ERK pathway inhibition enhanced sensitivity to 5-FU in Kirsten rat sarcoma (KRAS)-mutated or proto-oncogene B-rapidly accelerated fibrosarcoma $(B R A F)$ mutated CRC cell lines and murine colorectal tumor xenograft models (12-15). In a phase I study, the combination of the MEK1/2 inhibitor trametinib with neoadjuvant 5-FUbased chemoradiation in $K R A S / B R A F /$ neuroblastoma RAS viral oncogene homolog (NRAS)-mutated locally advanced rectal cancer demonstrated a pathological complete response 
in a patient identified to have the most significant reduction in ERK1/2 activity in post-treatment tumor tissue (16). MEK162 (ARRY-162 or binimetinib) is a novel, potent, and selective ATP-noncompetitive inhibitor of MEK1/2 that has proven anticancer activity against colorectal tumors in vitro and in vivo irrespective of RAS/RAF pathway mutations (1719). MEK162 has also shown synergistic antitumor activity when combined with cytotoxic chemotherapy paclitaxel and gemcitabine in pancreatic and CRC cell lines with an activated MAPK pathway (17).

Based on the above rationale, we propose that MEK inhibition may enhance the antitumor activity of nucleoside analogs 5-FU and trifluridine in CRC in the preclinical setting. We conducted an in vitro analysis of the antitumor efficacy of MEK162 combined with 5-FU or trifluridine in select CRC cell lines that were $K R A S / B R A F$ wild-type or mutant.

\section{Materials and Methods}

Cell lines and culture. All cell proliferation assays and drug cytotoxicity analyses were performed at the City of Hope National Medical Center (COH) Molecular Pathology Core Laboratory (Duarte, CA, USA). The following KRAS/BRAF-wild-type human CRC cell lines were utilized: $\mathrm{CaCO} 2$ obtained from the $\mathrm{COH}$ Molecular Pathology Core Laboratory (Duarte, CA, USA) and grown in Eagle's minimum essential medium (EMEM; Mediatech Inc., Manassas, VA, USA); COLO 320HSR obtained from the American Type Culture Collection (ATCC, cat. no. CCL-220.1) and grown in Roswell Park Memorial Institute (RPMI)-1640 medium (Mediatech Inc.); KM12 courtesy of Dr. YC (Duarte, CA, USA) and grown in Dulbecco's modified Eagle's medium (DMEM; Mediatech Inc.); and SNU-C1 obtained from the ATCC (cat.no. CRL-5972) and grown in RPMI-1640 medium. The HT29 human colorectal adenocarcinoma cell line was wild-type for KRAS but $B R A F^{\mathrm{V} 600 \mathrm{E}}$ mutated, obtained from the $\mathrm{COH}$ Molecular Pathology Core Laboratory (Duarte, CA), and grown in McCoy's 5A modified medium (Mediatech Inc.).

The following human CRC cell lines were $B R A F$ wild-type but harbored KRAS mutations and were obtained from the $\mathrm{COH}$ Molecular Pathology Core Laboratory : LS 174T (G12D), grown in EMEM; DLD-1 (G13D), grown in RPMI-1640 medium; HCT116 (G13D), grown in McCoy's 5A modified medium; and SW480 (G12V), grown in L-15 medium (Mediatech Inc.). Two human CRC cell lines DLD-1 DKO4 and HCT116 HKE3 had disrupted KRAS mutant alleles as described by Shirasawa et al. (20) and were grown in RPMI-1640 medium and DMEM, respectively. All cell lines were cultured at $37^{\circ} \mathrm{C}$ and under a humidified atmosphere with $5 \% \mathrm{CO}_{2}$ except for SW480, which was cultured at $37^{\circ} \mathrm{C}$ with standard atmosphere.

Cell treatment. Prior to 5-FU and MEK162 treatment (day 0), SW480, CaCO2, HCT116, HCT116 HKE3, DLD-1, and DLD-1 DKO4 cells were harvested when $75-80 \%$ confluent, seeded into 96well plates at $1500-2500$ cells/well in $100 \mu \mathrm{L}$ culture medium, and allowed to adhere for 24 hours. MEK162 (ARRY-438162; Array BioPharma Inc., Boulder, CO, USA) and 5-FU (Sigma-Aldrich, St. Louis, MO, USA) were prepared in dimethyl sulfoxide (DMSO) at stock concentrations of $2.27 \mathrm{mM}$ and $38.44 \mathrm{mM}$, respectively, and stored at $-20^{\circ} \mathrm{C}$. On day 1 , cells were then incubated with 5-FU alone in $50 \mu \mathrm{L}$ culture medium at final concentrations of $2,6,18$, and $54 \mu \mathrm{M}$, MEK162 alone in $50 \mu \mathrm{L}$ culture medium at final concentrations of $0.1,0.3,0.9$, and $2.7 \mu \mathrm{M}$, and combination of 5FU plus MEK162 in $50 \mu \mathrm{L}$ culture medium at final concentrations of $2 \mu \mathrm{M} 5$-FU plus $0.1 \mu \mathrm{M}$ MEK162, $6 \mu \mathrm{M}$ 5-FU plus $0.3 \mu \mathrm{M}$ MEK162, $18 \mu \mathrm{M}$ 5-FU plus $0.9 \mu \mathrm{M}$ MEK162, and $54 \mu \mathrm{M}$ 5-FU plus $2.7 \mu \mathrm{M}$ MEK 162 for 72 hours. On day 4, cell viability was analyzed using the 3-(4,5-dimethylthiazol-2-yl)-2,5-diphenyltetrazolium bromide (MTT) assay.

Prior to trifluridine and MEK162 treatment (day 0), LS 174T, DLD-1, HCT116, SW480, HT29, CaCO2, COLO 320HSR, KM12, and SNU-C1 cells were harvested when $75-80 \%$ confluent, seeded into 96-well plates at $1500-8000$ cells/well in $100 \mu \mathrm{L}$ culture medium, and allowed to adhere for 24 hours (suspension for COLO 320 HSR and SNU-C1 cell lines). MEK162 and trifluridine (courtesy of Dr. JW, the COH Animal Tumor Model Program, Duarte, CA, USA) stock solutions were prepared in DMSO at stock concentrations of $2.27 \mathrm{mM}$ and $10 \mathrm{mM}$, respectively, and stored at $-20^{\circ} \mathrm{C}$ degrees Celsius. On day 1 , cells were incubated with trifluridine in $50 \mu \mathrm{L}$ medium at final concentrations of $2,6,18$, and $54 \mu \mathrm{M}, \mathrm{MEK} 162$ in $50 \mu \mathrm{L}$ medium at final concentrations of 0.1 , $0.3,0.9$, and $2.7 \mu \mathrm{M}$, and combination of trifluridine plus MEK162 in $50 \mu \mathrm{L}$ medium at final concentrations of $2 \mu \mathrm{M}$ (trifluridine) plus $0.1 \mu \mathrm{M}$ (MEK162), $6 \mu \mathrm{M}$ (trifluridine) plus $0.3 \mu \mathrm{M}$ (MEK162), 18 $\mu \mathrm{M}$ (trifluridine) plus $0.9 \mu \mathrm{M}$ (MEK162), and $54 \mu \mathrm{M}$ (trifluridine) plus $2.7 \mu \mathrm{M}$ for 72 hours. On day 4 , cell proliferation was analyzed using the MTT assay. The cell number plated per well was determined by cell growth doubling time, size, and type of cell proliferation assay used. All experiments were performed using vehicle control in $50 \mu \mathrm{L}$ culture medium as a negative control.

Cell proliferation. Cell proliferation assays for 5-FU, trifluridine, and MEK162 treatments were performed using the MTT cell proliferation assay (Promega, Madison, WI, USA) as modified from the original assay described by Mosmann (21). The Promega MTT assay addresses several technical problems from the original method, but in principle remains a rapid colorimetric assay based on the conversion of MTT to its insoluble formazan crystal, which has a purple color specifically in viable cells.

Statistical analyses. All statistical analyses performed were descriptive and no formal statistical hypotheses were assessed. Drug concentrations were plotted against cell survival rates for all cell lines. The half maximal-inhibitory concentration $\left(\mathrm{IC}_{50}\right)$ for each cytotoxic treatment was calculated using the FORECAST function in Microsoft Excel. The combination index (CI) for combination treatments was expressed as the mean of the CI at effective dose of $50 \%\left(\mathrm{ED}_{50}\right)$ and calculated using CalcuSyn (Biosoft, Great Shelford, Cambridge, UK). Values of CI ranging from 0.1-0.3 suggest strong synergism, 0.3-0.7 synergism, and 0.7-0.9 slight synergism.

\section{Results}

Antitumor activity of 5-FU is greater in KRAS-mutated CRC cell lines than KRAS-wild-type cell lines. The human CRC cell lines CaCO2, SW480, DLD-1, DLD-1 DKO4, HCT116, and HCT116 HKE3 were all incubated with 2-54 $\mu \mathrm{M}$ 5-FU alone, 0.1-2.7 $\mu \mathrm{M}$ MEK162 alone and their combination for $72 \mathrm{~h}$ prior to analysis of cell viability by the MTT assay. The 
Gong et al: MEK162 in KRAS-mutated Human Colorectal Cancer Cell Lines

Table I. Half-maximal inhibitory concentrations for 5-flourouracil (5-FU) and mitogen-activated protein kinase kinase 162 (MEK162) and combination index (CI) for their combination for different human colorectal carcinoma cell lines. Data are the mean $\pm S D$.

\begin{tabular}{lccc}
\hline Cell line & 5-FU $(\mu \mathrm{M})$ & MEK162 $(\mu \mathrm{M})$ & CI* \\
\hline CaCO2 (KRAS/BRAF WT) & $23.59 \pm 2.18$ & $2.91 \pm 0.68$ & 0.46 \\
HCT116 HKE3 (KRAS disrupted allele/BRAF WT) & $12.36 \pm 2.26$ & $2.54 \pm 0.46$ & 2.53 \\
DLD-1 DKO4 (KRAS disrupted allele/BRAF WT) & $23.47 \pm 4.04$ & $1.99 \pm 0.20$ & 1.40 \\
SW480 $\left(K R A S^{\mathrm{G} 12 \mathrm{~V}}\right.$ MT) & $84.81 \pm 11.91$ & $2.05 \pm 0.16$ & 0.13 \\
HCT116 $\left(K R A S^{\mathrm{G} 13 \mathrm{D}} \mathrm{MT}\right)$ & $14.08 \pm 1.52$ & $1.71 \pm 0.15$ & 0.70 \\
DLD-1 $\left(K R A S^{\mathrm{G} 13 \mathrm{D}} \mathrm{MT}\right)$ & $26.35 \pm 3.21$ & $3.99 \pm 0.53$ & 0.90 \\
\hline
\end{tabular}

WT, Wild-type; MT, mutant. *Mean values at effective dose of 50\%, 0.1-0.3: strong synergism, 0.3-0.7: synergism, and 0.7-0.9: slight synergism.

Table II. Half maximal-inhibitory concentrations for trifluridine and mitogen-activated protein kinase kinase 162 (MEK162) and combination index (CI) for their combination for different human colorectal carcinoma cell lines. Data are the mean $\pm S D$.

\begin{tabular}{|c|c|c|c|}
\hline Cell line & Trifluridine $(\mu \mathrm{M})$ & $\operatorname{MEK} 162(\mu \mathrm{M})$ & $\mathrm{CI}^{*}$ \\
\hline $\mathrm{CaCO} 2($ KRAS/BRAF WT) & $76.97 \pm 2.61$ & $4.11 \pm 0.52$ & 1.35 \\
\hline COLO 320HSR (KRAS/BRAF WT) & $16.84 \pm 2.67$ & $11.25 \pm 1.20$ & 1.29 \\
\hline $\mathrm{KM} 12(K R A S / B R A F \mathrm{WT})$ & $44.12 \pm 13.40$ & $1.97 \pm 0.63$ & 0.83 \\
\hline SNU-C1 (KRAS/BRAF WT) & $44.76 \pm 3.12$ & $0.043 \pm 0.019$ & 0.04 \\
\hline $\mathrm{HT} 29\left(K_{R} A S^{\mathrm{V} 600 \mathrm{E}} \mathrm{MT}\right)$ & $77.45 \pm 4.17$ & $0.074 \pm 0.01$ & 0.25 \\
\hline LS 174T (KRASG12D MT) & $88.06 \pm 11.04$ & $0.21 \pm 0.02$ & 0.72 \\
\hline $\mathrm{SW} 480\left(K R A S^{\mathrm{G} 12 \mathrm{~V}} \mathrm{MT}\right)$ & $66.28 \pm 12.09$ & $1.88 \pm 0.37$ & 0.51 \\
\hline $\mathrm{HCT} 116\left(K R A S^{\mathrm{G} 13 \mathrm{D}} \mathrm{MT}\right)$ & $34.26 \pm 5.65$ & $1.21 \pm 0.20$ & 0.75 \\
\hline DLD-1 (KRAS $\left.S^{\mathrm{G} 13 \mathrm{D}} \mathrm{MT}\right)$ & $29.41 \pm 4.95$ & $2.48 \pm 0.27$ & 0.67 \\
\hline
\end{tabular}

WT, Wild-type; MT, mutant. *Mean values at effective dose of 50\%, 0.1-0.3: strong synergism, 0.3-0.7: synergism, and 0.7-0.9: slight synergism.

mean $\mathrm{IC}_{50}$ for 5-FU and MEK162 treatments and mean $\mathrm{CI}$ at $\mathrm{ED}_{50}$ for 5-FU plus MEK162 across cell lines are summarized in Table I.

Representative dose-survival curves for all 6 cell lines on treatment with 5-FU, MEK162, and their combination are illustrated in Figure 1. The lowest mean IC50 for 5-FU of $12.36 \pm 2.26 \mu \mathrm{M}$ was seen for HCT116 HKE3 (KRAS disrupted allele/BRAF wild-type) cell line, while the highest mean $\mathrm{IC}_{50}$ of $84.81 \pm 11.91 \mu \mathrm{M}$ was seen for SW480 (KRASG12V mutant/BRAF wild-type) cells. For MEK162, the lowest mean $\mathrm{IC}_{50}$ was $1.71 \pm 0.15 \mu \mathrm{M}$ observed for HCT116 (KRAS ${ }^{\mathrm{G} 13 \mathrm{D}}$ mutant/BRAF wild-type) cells and the highest mean $\mathrm{IC}_{50}$ was $3.99 \pm 0.53 \mu \mathrm{M}$ seen for DLD-1 (KRASG13D mutant/BRAF wild-type) cells.

The addition of MEK162 to 5-FU showed evidence of enhanced antitumor activity in the majority of cell lines (4/6). Combination 5-FU and MEK162 showed strong synergism in the KRAS-mutated SW480 cell line (CI=0.13) and $K R A S$-wild-type $\mathrm{CaCO} 2$ cell line $(\mathrm{CI}=0.46)$. Slight synergism was suggested in KRAS-mutated HCT116 $(\mathrm{CI}=0.70)$ and DLD-1 $(\mathrm{CI}=0.90) \mathrm{CRC}$ cells treated with their combination. Evidence of synergism was seen in all three
KRAS-mutated cell lines (SW480, HCT116, and DLD-1) treated with 5-FU plus MEK162. Notably, there was no evidence of synergism with 5-FU plus MEK 162 in the wildtype BRAF HCT116 HKE3 and DLD-1 DKO4 cell lines carrying disrupted $K R A S$-mutant alleles.

Antitumor activity of trifluridine is greater in CRC cell lines with KRAS or BRAF mutation than in wild-type cell lines. Nine human CRC cell lines LS 174T, DLD-1, HCT116, SW480, HT29, CaCO2, COLO 320HSR, KM12, and SNU-C1 were treated with trifluridine at concentrations of 2-54 $\mu \mathrm{M}$, MEK162 at concentrations of 0.1-2.7 $\mu \mathrm{M}$, and their combination for $72 \mathrm{~h}$ followed by evaluation of cell proliferation by MTT assay. Representative dose-survival curves for all nine cell lines treated with trifluridine, MEK162, and their combination are shown in Figure 2. Table II summarizes the mean $\mathrm{IC}_{50}$ for trifluridine and MEK162 treatments and mean CI at $\mathrm{ED}_{50}$ for trifluridine plus MEK162 across all cell lines. The lowest mean $\mathrm{IC}_{50}$ for trifluridine was $16.84 \pm 2.67 \mu \mathrm{M}$ for the wild-type KRAS/BRAF COLO 320HSR cell line, whereas the highest mean $\mathrm{IC}_{50}$ was $88.06 \pm 11.04 \mu \mathrm{M}$ for LS $174 \mathrm{~T} K R A S^{\mathrm{G} 12 \mathrm{D}}$ mutated cancer cells treated with trifluridine. Treatment of the 

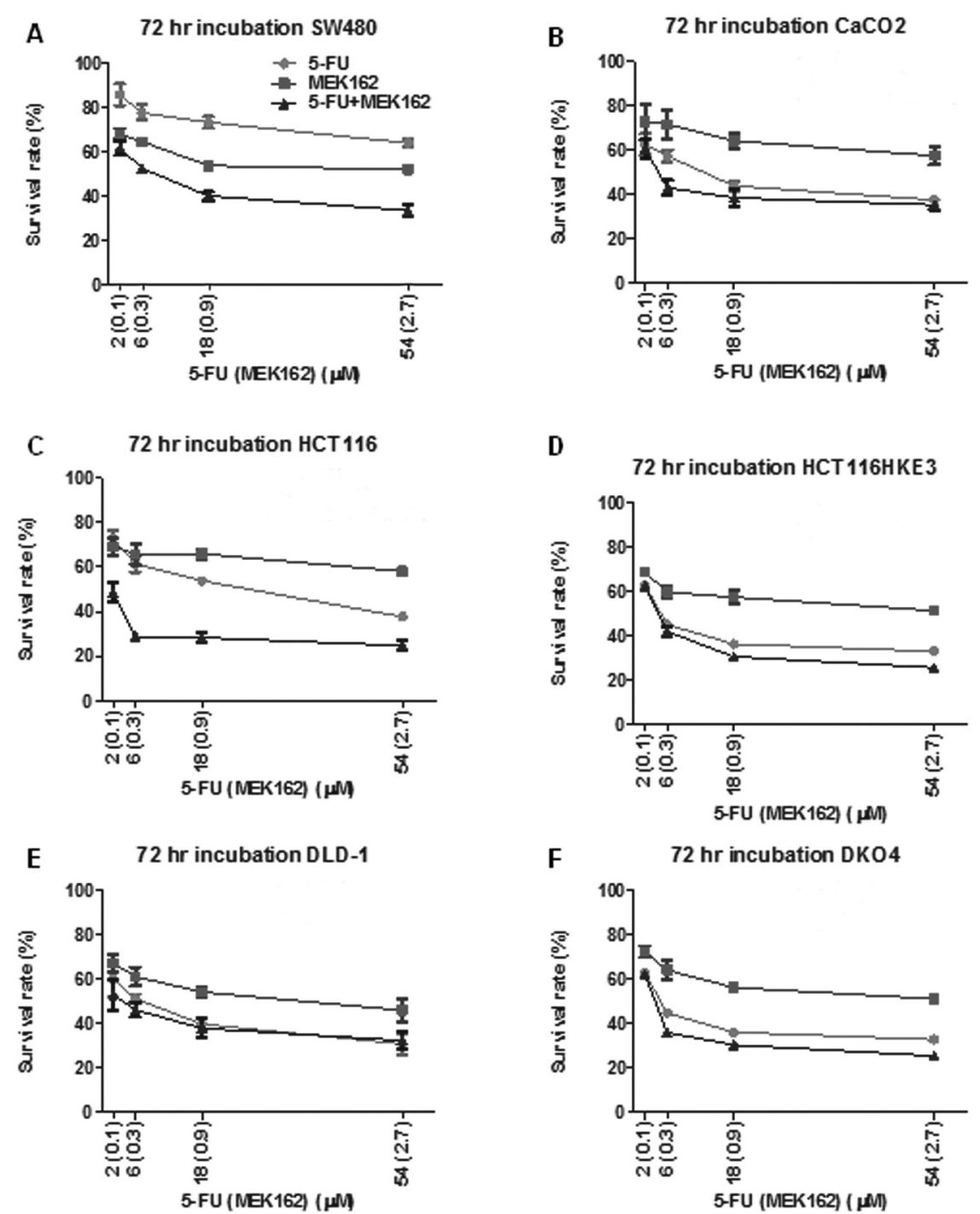

Figure 1. Mitogen-activated protein kinase kinase 162 (MEK162) and 5-fluorouracil (5-FU) demonstrate enhanced antitumor activity in human colorectal cancer cell lines. Dose-survival curves by 3-(4,5-dimethylthiazol-2-yl)-2,5-diphenyltetrazolium bromide (MTT) assay for 5-FU, MEK162, and 5-FU combined with MEK162 for KRAS-mutated SW480 (A), HCT116 (C), and DLD-1 (E) and the wild-type KRAS/BRAF CaCO2 (B) human colorectal carcinoma cell lines. Cell lines with a disrupted KRAS-mutant allele included HCT116 HKE3 (D) and DLD-1 DKO4 (F). X-Axis represents drug concentrations ( $\mu M)$ of 5-FU and MEK162 (in parentheses). Incubation period of 72 hours for all experiments.

SNU-C1 (KRAS/BRAF wild-type) cell line produced the lowest mean $\mathrm{IC}_{50}$ of $0.043 \pm 0.019 \mu \mathrm{M}$ for MEK162, while the highest mean $\mathrm{IC}_{50}$ for MEK162 was $11.25 \pm 1.20 \mu \mathrm{M}$ seen in COLO 320HSR cells.

Similar to the combination of 5-FU and MEK162, the addition of MEK162 to trifluridine showed evidence of enhanced antitumor activity in the majority of colorectal tumor cell lines (7/9). Evidence of strong synergism was observed with combination trifluridine plus MEK162 in the wild-type $K R A S / B R A F$ SNU-C1 cell line $(\mathrm{CI}=0.04)$ and
$B R A F^{\mathrm{V} 600 \mathrm{E}}$-mutated $\mathrm{HT} 29$ cell line $(\mathrm{CI}=0.25)$. The addition of MEK 162 to trifluridine also showed synergistic activity in KRAS-mutated SW480 and DLD-1 cells. Slight synergism was demonstrated in $2 K R A S$-mutated cell lines LS 174T and HCT 116 and one cell line with wild-type $K R A S / B R A F$, KM12, treated with the combination. Treatment with trifluridine plus MEK162 did not show evidence of synergism in wild-type KRAS/BRAF COLO 320HSR and $\mathrm{CaCO} 2$ cell lines. Evidence of increased activity with trifluridine plus MEK162 was greatest in cell lines carrying 

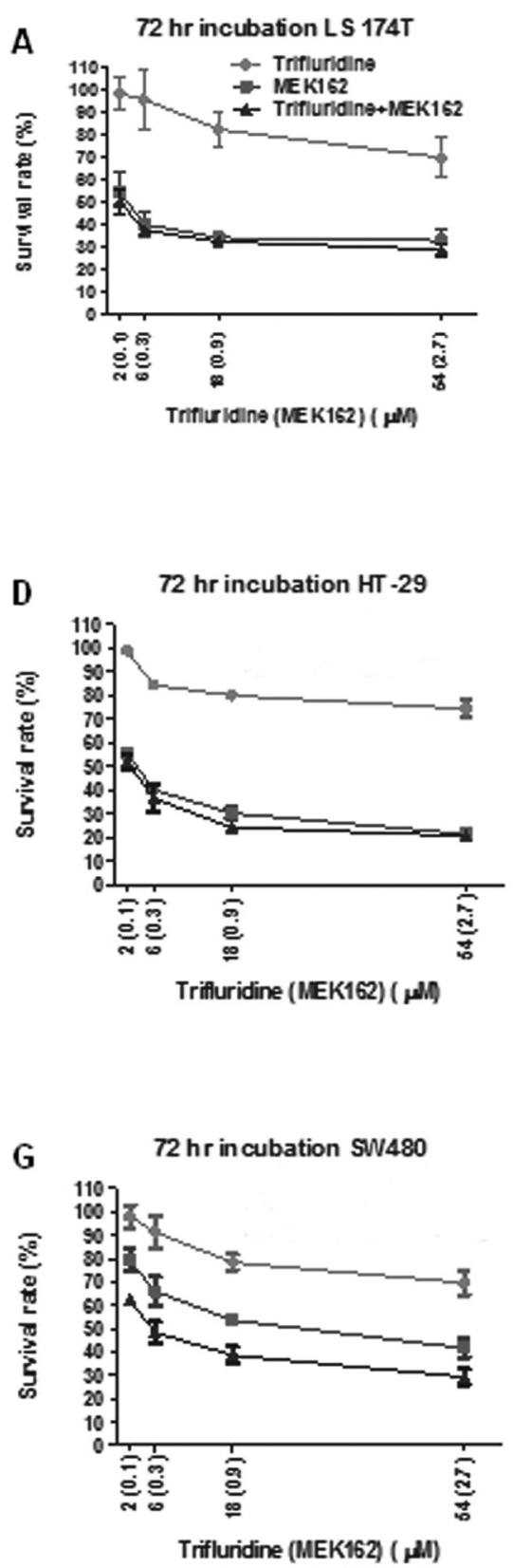
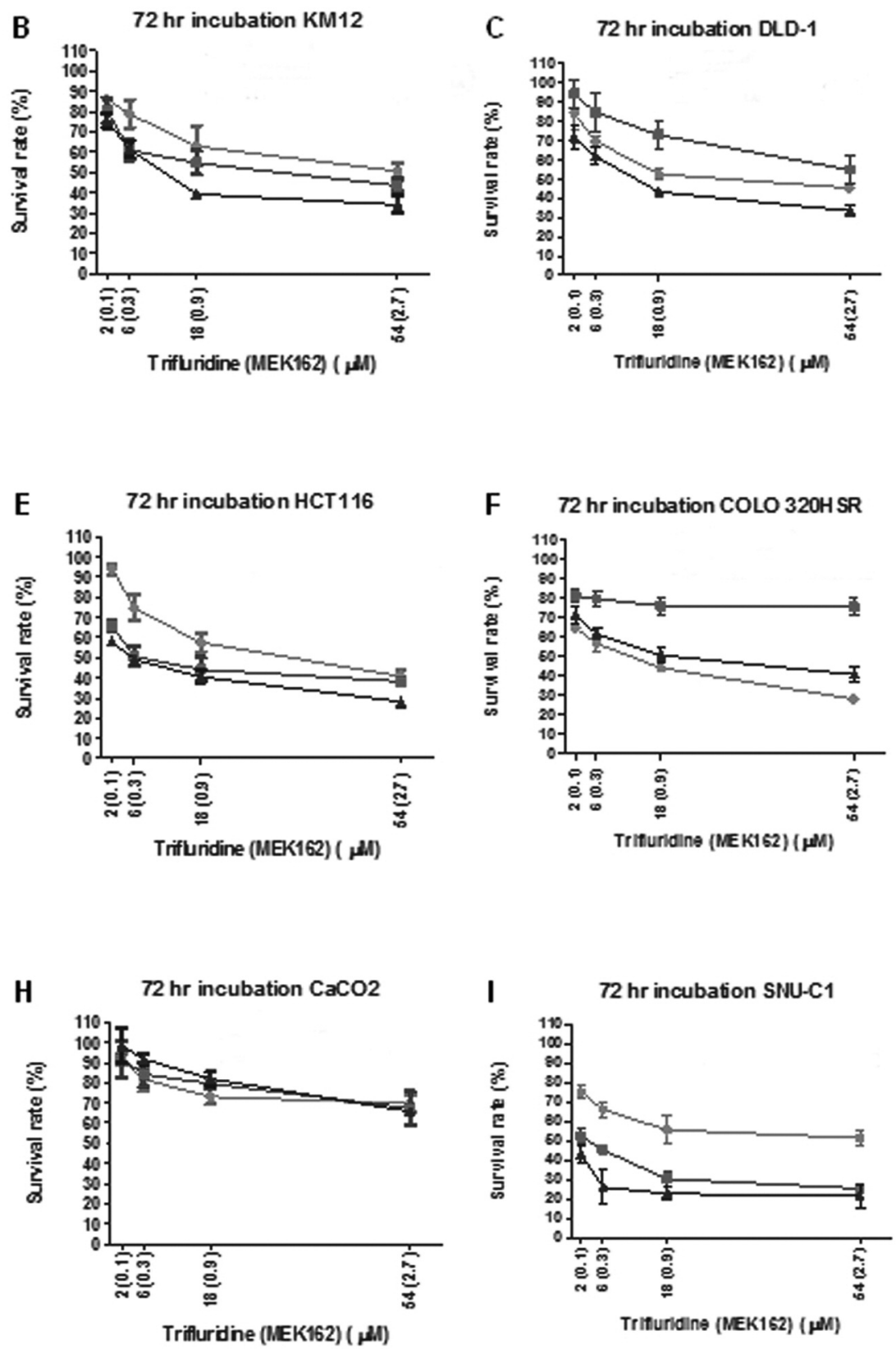

Figure 2. Mitogen-activated protein kinase kinase 162 (MEK162) and trifluridine demonstrate enhanced antitumor activity in human colorectal cancer cell lines. Dose-survival curves by 3-(4,5-dimethylthiazol-2-yl)-2,5-diphenyltetrazolium bromide (MTT) assay for trifluridine, MEK162, and trifluridine combined with MEK162 in KRAS-mutated LS 174T (A), DLD-1 (C), HCT116 (E), SW480 (G), and BRAF-mutated HT-29 (D) human colorectal carcinoma cell lines. Wild-type KRAS/BRAF cell lines included KM12 (B), COLO $320 H S R(F)$, CaCO2 (H), and SNU-C1 (I). X-Axis represents drug concentrations $(\mu M)$ of trifluridine, MEK162 (in parentheses). Incubation period of 72 hours for all experiments.

$K R A S$ or $B R A F$ mutations. All five $K R A S$ - or $B R A F$-mutant cell lines (SW480, DLD-1, LS 174T, HT29, and HCT 116) showed evidence of synergism, while only two out of four wild-type KRAS/BRAF cell lines (SNU-C1 and KM12) had enhanced activity when treated with their combination.

\section{Discussion}

The objective of this in vitro study was to determine whether addition of the MEK1/2 inhibitor MEK162 to 5-FU or trifluridine enhances antitumor efficacy in CRC cells in a 
$K R A S$ and/or BRAF mutation status-dependent manner. There is evidence in the literature supporting the role of MEK/ERK signaling in promoting resistance to fluoropyrimidines across several tumor types and the reversal of fluoropyrimidine resistance demonstrated by MEK/ERK pathway inhibition, particularly in CRC cells and animal models (8-15). Consistent with this, in this study, the addition of MEK162 to a nucleoside analog enhanced the antitumor activity in the majority of human CRC cell lines in both 5-FU (4/6) and trifluridine (7/9) experimental arms. The doses of 5-FU used for assessment of tumor cell viability (final concentrations of 2-54 $\mu \mathrm{M}$ ) are within the range of those examined in historic analyses of 5FU (0-50 $\mu \mathrm{M})$ cytotoxicity in human colorectal tumor cell lines similarly incubated for $72 \mathrm{~h}$ (22). Furthermore, our dose range of trifluridine $(2-54 \mu \mathrm{M})$ is within the range of doses examined in other preclinical cytotoxicity studies involving human CRC cell lines exposed to trifluridine $(0-35 \mu \mathrm{M})$ for $72 \mathrm{~h}(23)$. Treatment with MEK162 at doses of $0.1-2.7 \mu \mathrm{M}$ are comparable to those explored in human non-small cell lung cancer cell lines similarly treated with MEK $162(0.04-10 \mu \mathrm{M})$ for 72 hours (24). An even wider range of MEK162 dosing $(0.0001 \mu \mathrm{M}-10 \mu \mathrm{M})$ has been evaluated for cytotoxicity against human pancreatic cancer cell lines, but with an incubation period of 5 days (25). A lower range of MEK162 doses 25$200 \mathrm{nM}$ (72-h treatment) were used in cell proliferation assays of KRAS-mutated CRC cells, although in a combination study with palbociclib, and extrapolation of the dose-response curves of the MEK162 alone arm suggests that doses well beyond 200 $\mathrm{nM}$ are needed to reach $\mathrm{IC}_{50}$ for the majority of cell lines (26). Our dose range, as an example, produced an $\mathrm{IC}_{50}$ of $0.074 \mu \mathrm{M}$ for HT-29 cells that is concordant with the $\mathrm{IC}_{50}$ of $0.1 \mu \mathrm{M}$ seen in another preclinical study of HT-29 cells treated with escalating doses of MEK162 for $72 \mathrm{~h}$ (17).

The enhanced antitumor activity demonstrated with the addition of MEK162 to 5-FU or trifluridine was greater in CRC cell lines carrying KRAS or BRAF mutations than wildtype $K R A S / B R A F$ cell lines. Evidence of synergism was seen in all three KRAS-mutated cell lines (SW480, HCT116, and DLD-1) treated with 5-FU plus MEK162 but only in one wild-type $K R A S / B R A F$ cell line ( $\mathrm{CaCO} 2)$. All five mutant KRAS or BRAF cell lines (SW480, DLD-1, LS 174T, HT29, and HCT 116) showed evidence of synergism, while only two out of four wild-type $K R A S / B R A F$ cell lines (SNU-C1 and KM12) had enhanced activity when treated with trifluridine plus MEK162. Notably, treatment with trifluridine plus MEK162 demonstrated evidence of synergism in KRASmutated DLD-1 and HCT116 cell lines. However, in DLD-1 and HCT116 cell lines harboring disrupted KRAS alleles, we observed a loss of synergism when treated with 5-FU plus MEK162. DLD-1 DKO4 and HCT116 HKE3 are two human colon cancer cell lines that have wild-type $B R A F$ with $K R A S^{\mathrm{G} 13 \mathrm{D}}$ mutant alleles disrupted by homologous recombination; the resultant phenotypes differ from parental
KRAS-mutated phenotypes, with loss of anchorageindependent growth, decreased expression of $c-M Y C$, and slower growth in vitro and in vivo (20).

In an initial biomarker analysis of 218 solid cancer cell lines, MEK inhibition demonstrated increased activity across tumor cell lines carrying $R A S$ or $R A F$ mutations compared to cell lines wild-type for these genes (27). Sensitivity to MEK inhibition has also been demonstrated in CRC cell and mouse xenograft models harboring RAS or BRAF mutations $(28,29)$. Although MEK162 has demonstrated preclinical efficacy against both wild-type and mutant $K R A S / B R A F$ colorectal tumors, synergistic antitumor activity when combined with cytotoxic chemotherapy such as paclitaxel and gemcitabine was demonstrated in pancreatic and CRC cell lines with an activated MAPK pathway $(17,19)$. In the preclinical studies showing the activity of combined MEK/ERK pathway inhibition and 5-FU therapy, all were carried out on either $K R A S$-mutated or $B R A F$-mutated CRC cell lines (12-15). Overall, our findings are consistent with the literature and support the concept that the presence of $K R A S$ or $B R A F$ mutations are critical in eliciting more meaningful responses from the addition of MEK162.

Crosstalk between pathways parallel to, downstream of, or unrelated to the canonical RAS/RAF/MEK/ERK signaling pathway may affect response to the addition of MEK inhibition to combination therapy in cancer cells. Although $R A S / R A F$ mutations are among the primary predictors of sensitivity to MEK inhibition, resistance appears to be mediated by phosphoinositide 3-kinase (PIK3) signaling (27, $28)$. Furthermore, in $K R A S$-mutated human colorectal tumor cell lines, activating $P I K 3 C A$ mutations reduced sensitivity to MEK inhibition, whereas phosphatase and tensin homolog (PTEN) mutations (loss of PTEN function) conferred complete resistance (30). Indeed, in our three KRAS-mutated cell lines (SW480, HCT116, and DLD-1) treated with 5-FU plus MEK162, the strongest synergism was seen in SW480 cells (CI 0.13), which are known to be PIK3CA/PTEN-wildtype, while slight synergism $(\mathrm{CI}=0.70-0.90)$ was observed in HCT116 and DLD-1 cells, which are PIK3CA-mutated but $P T E N$-wild-type (31). In the KRAS or BRAF-mutated cell lines treated with trifluridine plus MEK162, the strongest evidence of synergism was seen in HT29 ( $\mathrm{CI}=0.25)$ and SW480 cells $(\mathrm{CI}=0.51)$. SW480 cells, as described previously, are wild-type for PIK3CA and PTEN. Interestingly, HT29 cells are wild-type for KRAS and PTEN but $B R A F / P I K 3 C A$-mutated (31). It has been shown that tumor cells carrying $B R A F^{\mathrm{V} 600 \mathrm{E}}$ and $P I K 3 C A$ mutations have relatively lower expression of resistance genes and more varied sensitivity to MEK inhibition (28). Accordingly, less synergism was seen in our $K R A S$-mutated cell lines LS 174T, HCT116, and DLD-1 harboring PIK3CA mutations. A separate study described that PI3K/AKT pathway inhibition has a greater effect than MEK/ERK pathway inhibition on 
reversing resistance to cytotoxics, including 5-FU (9). Intuitively, targeting multiple steps along the MAPK signaling cascade, for example, by dual MEK and PI3K or AKT inhibition, may provide additional avenues of therapeutic benefit $(18,32)$.

Moreover, the ability of MEK/ERK pathway inhibition to increase sensitivity to 5-FU in human colon cancer cells appears dependent on the presence of wild-type $p 53$ and related mediators p21, p53-up-regulated modulator of apoptosis (PUMA), c-Jun $N$-terminal kinase (JNK), and p38 MAPK (12). Anti-apoptotic proteins downstream of AKT including B-cell lymphoma XL (BCL-xL) and myeloid cell leukemia 1 (MCL1) have also been implicated in 5-FU resistance (14). Further investigation into molecular phenotypes of potential significance to the efficacy of MEK inhibition and fluoropyrimidine therapy is prudent to understanding resistance and optimizing response to this regimen in CRC.

Lastly, the combination of MEK inhibition and trifluridine can serve an unmet need in the treatment paradigm of mCRC. The development of first-line and second-line regimens involving 5-FU-based combination therapy with the addition of anti-epidermal growth factor receptor and anti-vascular endothelial growth factor A inhibitors in select populations have afforded improved survival in mCRC (33). Despite these advances, it appears that we have reached a plateau in OS in mCRC treatment, and resistance to 5-FU ultimately develops through the treatment course. TAS-102 as a late-line treatment in mCRC offers slight benefit, but progression eventually occurs. The integration of MEK inhibition increases sensitivity to trifluridine in colorectal tumor cell lines and may represent a viable option in treatment-refractory $K R A S / B R A F$-mutated mCRC that has progressed through all standard therapies.

In conclusion, the addition of MEK162 to 5-FU or trifluridine demonstrated synergistic antitumor activity in the majority of human colorectal tumor cell lines evaluated here. Evidence of synergism appears to be increased in KRAS- or $B R A F$-mutant cell lines compared to wild-type $K R A S / B R A F$ CRC cell lines. The combination of MEK inhibition and trifluridine represents a potentially viable option in KRASor $B R A F$-mutated mCRC that is worthwhile to advance in clinical development.

\section{References}

1 Meyerhardt JA and Mayer RJ: Systemic therapy for colorectal cancer. N Engl J Med 352: 476-487, 2005.

2 de Gramont A, Figer A, Seymour M, Homerin M, Hmissi A, Cassidy J, Boni C, Cortes-Funes H, Cervantes A, Freyer G, Papamichael D, Le Bail N, Louvet C, Hendler D, de Braud F, Wilson C, Morvan F and Bonetti A: Leucovorin and fluorouracil with or without oxaliplatin as first-line treatment in advanced colorectal cancer. J Clin Oncol 18: 2938-2947, 2000.
3 Falcone A, Ricci S, Brunetti I, Pfanner E, Allegrini G, Barbara C, Crinò L, Benedetti G, Evangelista W, Fanchini L, Cortesi E, Picone V, Vitello S, Chiara S, Granetto C, Porcile G, Fioretto L, Orlandini C, Andreuccetti M, Masi G and Gruppo Oncologico Nord Ovest: Phase iii trial of infusional fluorouracil, leucovorin, oxaliplatin, and irinotecan (folfoxiri) compared with infusional fluorouracil, leucovorin, and irinotecan (folfiri) as first-line treatment for metastatic colorectal cancer: The gruppo oncologico nord ovest. J Clin Oncol 25: 1670-1676, 2007.

4 Fuchs CS, Marshall J, Mitchell E, Wierzbicki R, Ganju V, Jeffery M, Schulz J, Richards D, Soufi-Mahjoubi R, Wang B and Barrueco J: Randomized, controlled trial of irinotecan plus infusional, bolus, or oral fluoropyrimidines in first-line treatment of metastatic colorectal cancer: Results from the bicc-c study. J Clin Oncol 25: 4779-4786, 2007.

5 Goldberg RM, Sargent DJ, Morton RF, Fuchs CS, Ramanathan RK, Williamson SK, Findlay BP, Pitot HC and Alberts SR: A randomized controlled trial of fluorouracil plus leucovorin, irinotecan, and oxaliplatin combinations in patients with previously untreated metastatic colorectal cancer. J Clin Oncol 22: 23-30, 2004.

6 Tanaka N, Sakamoto K, Okabe H, Fujioka A, Yamamura K, Nakagawa F, Nagase H, Yokogawa T, Oguchi K, Ishida K, Osada A, Kazuno H, Yamada Y and Matsuo K: Repeated oral dosing of tas-102 confers high trifluridine incorporation into DNA and sustained antitumor activity in mouse models. Oncol Rep 32: 2319-2326, 2014.

7 Mayer RJ, Van Cutsem E, Falcone A, Yoshino T, GarciaCarbonero R, Mizunuma N, Yamazaki K, Shimada Y, Tabernero J, Komatsu Y, Sobrero A, Boucher E, Peeters M, Tran B, Lenz HJ, Zaniboni A, Hochster H, Cleary JM, Prenen H, Benedetti F, Mizuguchi H, Makris L, Ito M, Ohtsu A and RECOURSE Study Group: Randomized trial of tas-102 for refractory metastatic colorectal cancer. N Engl J Med 372: 1909-1919, 2015.

8 Gomes E, Jennings-Gee $\mathrm{J}$ and Gmeiner WH: The mek/erk pathway is required for pc3 cell survival following fdump[10] treatment [abstract]. Cancer Res 70: Abstract nr 1637, 2010.

9 Jin W, Wu L, Liang K, Liu B, Lu Y and Fan Z: Roles of the pi$3 \mathrm{k}$ and mek pathways in ras-mediated chemoresistance in breast cancer cells. Br J Cancer 89: 185-191, 2003.

10 Yan Y, Li J, Han J, Hou N, Song Y and Dong L: Chlorogenic acid enhances the effects of 5-fluorouracil in human hepatocellular carcinoma cells through the inhibition of extracellular signalregulated kinases. Anticancer Drugs 26: 540-546, 2015.

11 Zhang Z, Zhou X, Shen H, Wang D and Wang Y: Phosphorylated erk is a potential predictor of sensitivity to sorafenib when treating hepatocellular carcinoma: Evidence from an in vitro study. BMC Med 7: 41, 2009.

12 Pereira DM, Simões AE, Gomes SE, Castro RE, Carvalho T, Rodrigues CM and Borralho PM: Mek5/erk5 signaling inhibition increases colon cancer cell sensitivity to 5-fluorouracil through a p53-dependent mechanism. Oncotarget 7: 34322-34340, 2016.

13 Urick ME, Chung EJ, Shield WP, Gerber N, White A, Sowers A, Thetford A, Camphausen K, Mitchell J and Citrin DE: Enhancement of 5-fluorouracil-induced in vitro and in vivo radiosensitization with mek inhibition. Clin Cancer Res 17: 5038-5047, 2011.

14 Watanabe M, Sowa Y, Yogosawa M and Sakai T: Novel mek inhibitor trametinib and other retinoblastoma gene (rb)reactivating agents enhance efficacy of 5-fluorouracil on human colon cancer cells. Cancer Sci 104: 687-693, 2013. 
15 Yang SY, Miah A, Sales KM, Fuller B, Seifalian AM and Winslet M: Inhibition of the p38 mapk pathway sensitises human colon cancer cells to 5-fluorouracil treatment. Int J Oncol 38: 1695-1702, 2011

16 Williams TM, Wuthrick E, Wu C, Robb R, Timmers C and Bekaii-Saab T: A phase i trial combining mek-1/2 inhibition in combination with 5-fluorouracil and radiation for kras, braf, and nras mutant locally advanced rectal adenocarcinoma [abstract]. Cancer Res 76: Abstract nr CT025, 2016.

17 Woessner R, Winski S, Rana S, Anderson D, Winkler J and Lee P: Arry-162, a potent and selective mek $1 / 2$ inhibitor, shows enhanced efficacy in combination with other targeted kinase inhibitors and with chemotherapy [abstract]. Cancer Res 70: Abstract 2514, 2010.

18 Raja M, Zverev M, Seipel K, Williams GT, Clarke AR and Shaw $\mathrm{PH}$ : Assessment of the in vivo activity of pi3k and mek inhibitors in genetically defined models of colorectal cancer. Mol Cancer Ther 14: 2175-2186, 2015.

19 Winski S, Anderson D, Bouhana K, Rhodes S, Impastato R, Woessner R, Zuzack J, Tunquist B, Garrus J, Pheneger T and Lee P: Mek162 (arry-162), a novel mek 1/2 inhibitor, inhibits tumor growth regardless of kras/raf pathway mutations. Eur J Cancer Suppl 8: 56, 2010.

20 Shirasawa S, Furuse M, Yokoyama N and Sasazuki T: Altered growth of human colon cancer cell lines disrupted at activated ki-ras. Science 260: 85-88, 1993.

21 Mosmann T: Rapid colorimetric assay for cellular growth and survival: Application to proliferation and cytotoxicity assays. J Immunol Methods 65: 55-63, 1983.

22 Calabro-Jones PM, Byfield JE, Ward JF and Sharp TR: Timedose relationships for 5-fluorouracil cytotoxicity against human epithelial cancer cells in vitro. Cancer Res 42: 4413-4420, 1982.

23 Bijnsdorp IV, Peters GJ, Temmink OH, Fukushima M and Kruyt FA: Differential activation of cell death and autophagy results in an increased cytotoxic potential for trifluorothymidine compared to 5-fluorouracil in colon cancer cells. Int J Cancer 126: 24572468,2010

24 Yao W, Yue P, Zhang G, Owonikoko TK, Khuri FR and Sun SY: Enhancing therapeutic efficacy of the mek inhibitor, mek162, by blocking autophagy or inhibiting pi3k/akt signaling in human lung cancer cells. Cancer Lett 364: 70-78, 2015.

25 Hamidi H, Lu M, Chau K, Anderson L, Fejzo M, Ginther C, Linnartz R, Zubel A, Slamon DJ and Finn RS: Kras mutational subtype and copy number predict in vitro response of human pancreatic cancer cell lines to mek inhibition. Br J Cancer 111: 1788-1801, 2014
26 Lee MS, Helms TL, Feng N, Gay J, Chang QE, Tian F, Wu JY, Toniatti C, Heffernan TP, Powis G, Kwong LN and Kopetz S: Efficacy of the combination of mek and cdk4/6 inhibitors in vitro and in vivo in kras mutant colorectal cancer models. 2016 7: 39595-39608, 2016.

27 Jing J, Greshock J, Holbrook JD, Gilmartin A, Zhang X, McNeil E, Conway T, Moy C, Laquerre S, Bachman K, Wooster R and Degenhardt Y: Comprehensive predictive biomarker analysis for mek inhibitor gsk1120212. Mol Cancer Ther 11: 720-729, 2012.

28 Dry JR, Pavey S, Pratilas CA, Harbron C, Runswick S, Hodgson D, Chresta C, McCormack R, Byrne N, Cockerill M, Graham A, Beran G, Cassidy A, Haggerty C, Brown H, Ellison G, Dering J, Taylor BS, Stark M, Bonazzi V, Ravishankar S, Packer L, Xing F, Solit DB, Finn RS, Rosen N, Hayward NK, French T and Smith PD: Transcriptional pathway signatures predict mek addiction and response to selumetinib (azd6244). Cancer Res 70: 2264-2273, 2010.

29 Guinney J, Ferté C, Dry J, McEwen R, Manceau G, Kao KJ, Chang KM, Bendtsen C, Hudson K, Huang E, Dougherty B, Ducreux M, Soria JC, Friend S, Derry J and Laurent-Puig P: Modeling ras phenotype in colorectal cancer uncovers novel molecular traits of ras dependency and improves prediction of response to targeted agents in patients. Clin Cancer Res 20: 265$272,2014$.

30 Wee S, Jagani Z, Xiang KX, Loo A, Dorsch M, Yao YM, Sellers WR, Lengauer $\mathrm{C}$ and Stegmeier F: Pi3k pathway activation mediates resistance to mek inhibitors in kras mutant cancers. Cancer Res 69: 4286-4293, 2009.

31 Ahmed D, Eide PW, Eilertsen IA, Danielsen SA, Eknæs M, Hektoen M, Lind GE and Lothe RA: Epigenetic and genetic features of 24 colon cancer cell lines. Oncogenesis 2: e71, 2013.

32 Migliardi G, Sassi F, Torti D, Galimi F, Zanella ER, Buscarino M, Ribero D, Muratore A, Massucco P, Pisacane A, Risio M, Capussotti L, Marsoni S, Di Nicolantonio F, Bardelli A, Comoglio PM, Trusolino L and Bertotti A: Inhibition of mek and pi3k/mtor suppresses tumor growth but does not cause tumor regression in patient-derived xenografts of ras-mutant colorectal carcinomas. Clin Cancer Res 18: 2515-2525, 2012.

33 Gong J, Cho M and Fakih M: Ras and braf in metastatic colorectal cancer management. J Gastrointest Oncol 7: 687-704, 2016.

Received April 12, 2017

Revised April 30, 2017

Accepted May 3, 2017 